\title{
Dimensiones conceptuales, políticas y ético-religiosas de la agenda internacional del medio ambiente para el siglo XXI
}

\section{Claude Pomerleau / José A.Morandé}

Las informaciones experimentadas en la agenda internacional a fines del siglo $X X$ han puesto de relieve la trascendencia de temas y problemas que preocupan a la sociedad civil, desafiando con ello no sólo a la estructura institucional y actores tradicionales del sistema mundial sino que también a las visiones y formas de observar; explicar y prescribir la realidad intemacional de nuestros días. La internacionalidad y globalización del problema medio-ambiental es abordado en este artículo desde una perspectiva amplia y actualizada de las Relaciones Internacionales, para lo cual junto con identificar a los actores internacionales más importantes relacionados con el tema, se discute la validez y alcance de los esquemas sociales, económicos, de seguridady morales que interpretan las decisiones y políticas adoptadas y por adoptar en este campo. Finalmente, el articulo al contrastar y evaluar los avances y retrocesos del problema medioambiental a nivel mundial, sugiere como tarea urgente hoy, el desarrollo de una ética antes de que colapse el ecosistema bajo el peso del progreso y del desarrollo económico. En otras palabras, el logro de un adecuado equilibrio entre justicia socio-económica y justicia ecológica como una tarea propuesta para toda la humanidad, hace suya también las dimensiones ecológicas y teologicas que plantean algunas iglesias, en orden a lograr un "justo desarrollo humano sustentable" y el "bien comín planetario" incorporando todo lo de la creación, esto es, lo humano como también lo no humano. 


\section{Introducción}

Para los cientistas políticos, la elaboración y aprobación de políticas medio-ambientales globales ha sido uno de los desarrollos más significativos de la segunda mitad del siglo XX, tanto en el nivel local como mundial. A partir del fin de la Guerra Fría, la rígida y polarizada estructura política se transforma en algo mucho más fluido y complejo. Esta transformación ha desafiado a especialistas y al ciudadano común a pensar nuevamente sobre la comprensión de temas básicos la política.

Este trabajo pretende examinar las principales tendencias en las políticas globales y locales como expresión de las necesidades y desafíos medio-ambientales. Además, se propone la revisión de la gran cantidad de demandas sobre estos temas que enfrentan quienes tratan de formular políticas globales. A este respecto, muchos especialistas ya han entrado en la arena del medio ambiente, desafiando a los responsables de las decisiones políticas a redefinir estas materias, como así también las de carácter social, cultural, religioso y económico.

Para lo anterior, es necesario primeramente identificar a los actores institucionales de mayor alcance -muchos de los cuales son nuevos -que vinculan políticas globales, nacionales y locales. En seguida, en qué medida éstos formulan un esquema adecuado para la explicación de los tópicos ambientales y cómo ellos influencian a la esfera política. Finalmente, se discutirán las respuestas específicas de políticas a las nuevas demandas del ecosistema.

El estudio de los temas medio-ambientales y sus correspondientes regímenes políticos ha llegado a ser un esfuerzo complejo, pleno de desafíos controvertidos y sugerentes en la disciplina de las Relaciones Internacionales. La protección del medio ambiente ha influenciado la forma de cómo entendemos y hacemos política en todos los niveles y en todas las áreas. Existen muchas controversias entre los estudiosos de las Relaciones Internacionales debido a las contradicciones y ambigüedades que caracterizan los nuevos y rápidos cambios en los datos de la ciencia, economía y otras disciplinas. Hasta hace poco, los aspectos ambientales preocupaban solamente a pocas personas del mundo desarrollado, pero ahora es raro verificar que diplomáticos y políticos, de los países ricos y desarrollados como también de las naciones pobres, no estén preocupados de una amplia gama de tales temas.

Por otra parte, también se han generado muchos desacuerdos entre los analistas respecto del significado y dirección de las políticas globales sobre el 
medio ambiente. Estas diferencias surgen en relación con las teorías a utilizar para la explicación y control de los rápidos y profundos cambios en las políticas sobre el desarrollo y su significado para la sustentación del mismo. Así, el llamado desarrollo sustentable, esto es, el enfoque o perspectiva para la asistencia internacional que otorga primera importancia a la promoción de la política de auto- ayuda, también ha sido fuertemente influenciado por los temas medio ambientales.

Las macro tendencias globales que configuran la segunda mitad del siglo XX constituyen pre-requisitos esenciales para entender la importancia de los estudios ecológicos en el campo de la disciplina de las Relaciones Internacionales. Las tendencias que a continuación se indican son cruciales en la comprensión de los problemas que enfrentan los especialistas que deben formular políticas en el ámbito medio ambiental: I.- el rápido e inesperado crecimiento en la producción industrial y energética de los países en desarrollo; $\Pi$.- el reciente y veloz crecimiento de la población y el incremento de las expectativas de vida; III.- el revolucionario desarrollo - un concepto cuyo uso es apropiado en este caso- en las tecnologías de comunicación y transporte, tanto en sus aplicaciones civil y militar, y finalmente, sin tratar de ser completamente inclusivo; TV.- el continuo estado de desorganización global (muchos aun prefieren llamar a esto anarquía) en el cual los aproximadamente 189 estados-naciones de la tierra continúan configurando las políticas globales. Los expertos siguen hablando de un desconcertante "desajuste" entre la estructura política de los estados y el ordenado desarrollo de los regímenes considerados esenciales para un futuro seguro y a salvo '.

Por otra parte, los especialistas que estudian la política del poder desde la perspectiva de la seguridad del estado han expresado generalmente su malestar con el lenguaje de la ética y moralidad cuando discuten las políticas desde esa perspectiva. Sin embargo, teólogos y moralistas han venido examinando por algún tiempo la importancia de los valores religiosos y morales en la política internacional, especialmente para entender el área de los derechos humanos y del medio ambiente.

Lo anterior es corroborado por José Casanova cuando se refiere a la gravitación que ha adquirido la presencia de las religiones en el escenario internacional. En efecto, nos señala este autor que las diversas manifestaciones a través 
del mundo están entrando en la esfera pública y en los dominios del campo político, no sólo para defender su terreno tradicional sino que también para participar, a modo de ejemplo, en las disputas sobre la definición y ubicación de los límites modernos entre lo privado y lo público, los alcances entre legalidad y moralidad, entre familia, sociedad civil y estado; como así también, entre naciones, estados y sistema mundial ${ }^{2}$.

El hecho de que hayan surgido normas globales para los derechos humanos y para la protección de los bienes comunes globales ha empezado a tomar fuerza en los grupos de trabajo de los políticos y los estudiosos. La política internacional tradicional ha estado dominada por expertos quienes se han especializado en la teoría y aplicación del poder militar y del estado. Para ellos los debates fueron limitados a los filósofos y a los científicos sociales quienes se concentran en el lenguaje tradicional de balance de poder, disuasión y seguridad. No obstante, con la creciente complejidad de este mundo interdependiente, el estudio del ambiente, derechos humanos, sociedad civil global y temas económicos relacionados han llegado a ser tan relevantes para el estudio de las relaciones internacionales como la alta política de la guerra y la paz reflejadas a través de alianzas y la aplicación del poder militar. ${ }^{3}$

\section{Identificación de los principales actores globales}

En la actualidad son muchos los agentes involucrados en la formulación de las políticas medio ambientales. Los más relevantes son los estados naciones, las organizaciones intergubernamentales y las organizaciones (civiles) globales no gubernamentales tales como Amnesty International, como asimismo la mayoría de organizaciones regionales especializadas, entre ellas la Union of Concerned Scientists. Examinaremos a continuación estas tres categorías de actores:

\footnotetext{
2 José Casanova, Public Religions in the Modem World (Chicago: The University of Chicago Press, 1994) pág 6

3 Por ejemplo, es interesante comparar los textos de relaciones internacionales desde los años cuarenta y cincuenta como los de Hans J. Morgenthau, Politics Among Nations (3d ed. New York: Knopf, 1956) con textos más recientes como el de Bruce Russet y Harvey Starr, World Politics. The Menu for Choice (4 ed. New York: W.H. Freeman, 1992) o Barry B. Hughes, Continuity and Change in World Politics: The Clash of Perspectives (and ed. New York: Prentice Hall, 1994).
} 


\section{Estados Naciones}

Las interacciones de los estados naciones entre ellos, todavía constituyen el cuerpo de lo que se conoce como las relaciones internacionales. Sus luchas por status internacional e identidad generalmente conducen al conflicto, pero para su supervivencia, usualmente requieren de la cooperación. Hasta hace muy poco, los temas del desarrollo, seguridad, medio ambiente y derechos humanos fueron considerados como un monopolio de los estados soberanos. Este monopolio como característica soberana de los estados está siendo amenazado por la acción de los actores y organizaciones no estatales, cuyo origen y gestación se encuentran en la sociedad civil nacional e internacional. Del mismo modo, las capacidades de los estados han cambiado drásticamente, haciendo que los modos económicos de ejercer influencia se estén incrementando notablemente, lo mismo que la influencia de individuos y grupos sociales.

Algunos desafíos del mundo actual, incluyendo aquellos de los grupos étnicos, provienen desde el mismo estado. Otras demandas al estado, tales como aquellas que emanan de las iglesias, organizaciones de derechos humanos y de empresas económicas y comerciales tienen su origen más allá de la esfera soberana de los estados. En realidad, el desafío actual a la soberanía de los estados proviene tanto de factores internos como externos. En la interacción de factores diversos de la esfera política doméstica con elementos, instituciones y políticas internacionales hace que muchas veces el ejercicio de la soberanía sea cuestionable desde el punto de vista de los parámetros tradicionales. En este sentido, cobra importancia el cálculo de costos y beneficios que los estados deben evaluar a los efectos de ceder o no parte de sus soberanías.

De esta forma, los procesos de expansión creciente de la sociedad civil internacional y de adecuación de los estados a esta nueva realidad global no sólo promueven la identificación y participación de actores e instituciones distintos a los estados y sus gobiernos, sino que también reconocen la influencia, a veces decisiva, que ejercen tales agentes en las políticas públicas adoptadas por los propios estados. Asimismo, esta influencia contiene elementos valóricos y morales, los cuales en ocasiones se transforman en factores legitimadores de las políticas de estado en relación a las demandas y aspiraciones de la humanidad.

Hoy, es casi una trivialidad decir que el poder tradicional de los estados ha sido constreñido severamente por los mercados globales. No obstante, aque- 
llos representan las mismas fuerzas de mercado, políticas e ideológicas que hicieron colapsar a los regímenes comunistas en Europa Central y que dieron nueva vida a las políticas locales en China. Los productos de multinacionales como las "zapatillas" Nike y los "walkman" Sony han hecho tanto, a su manera, para debilitar al poder tradicional del estado como el terrorismo y las armas de destrucción masiva. ${ }^{4}$ Del mismo modo, el creciente conjunto de acuerdos multilaterales y regulaciones internacionales está transformando cada vez más, la vieja forma de liderazgo tipo "cowboy" que caracterizó a las relaciones internacionales durante la Guerra Fría. En otras palabras, en la actualidad y en este nuevo escenario internacional interdependiente, para que los estados tengan éxito se requiere mucho más que poder bruto y fuerza militar.

Sin embargo, existen todavía muchos países, tanto en el mundo desarrollado como en vías de desarrollo que rápidamente recurren a la fuerza o a la intimidación cuando los temas medio ambientales o de derechos humanos bloquean sus intereses. ${ }^{5}$ Aunque es interesante constatar que no siempre los países poderosos como la agrupación de las economías más grandes del mundo e identificadas como el Grupo de los Siete, G-7 (Estados Unidos, Canadá, Japón, Alemania, Italia, Francia y el Reino Unido) son los que proveen el liderazgo más creativo para los temas globales medio ambientales. Pequeños estados con economías marginales o reducidas como Costa Rica, Noruega, Suecia y Finlandia han sido autores de propuestas imaginativas para resolver problemas del medio ambiente, mostrando al mismo tiempo, más creatividad que muchos países más grandes y más ricos.

Gareth Porter y Janet Welsh Brown ${ }^{6}$ han demostrado que los temas domésticos, económicos y políticos, influyen fuertemente en el papel que los diferentes estados asumen en la arena de las políticas medio ambientales. Estados grandes como la India, Indonesia, Brasil y México se han resistido a adoptar políticas ambientales debido a las presiones de grupos domésticos organizados. Mientras que una nación pequeña como Costa Rica ha llegado a ser un modelo de programas innovativos de protección contra la lluvia ácida. También es significativo que países occidentales gravitantes en el escenario mun-

4 Nicholas Boyle, Who Are We Now? Christian Humanism and the Global Market from Hegel to Heaney (Notre Dame, Ind.: University of Notre Dame Press, 1998). Para una discusión relevante sobre la transformación del poder del estado, véase el capítulo "After History", pág 70.93

5 Gareth Porter y Janet Welsh Brown, Global Environmental Politics (2nd ed. Boulder, Colo.: Westview Press, 1996) pág. 36

${ }^{6}$ Ibid. $33-39$ 
dial, como Estados Unidos, Francia y Alemania, poseen poderosos e influyentes lobbies internacionales de protección del medio ambiente.

De la misma manera, países ricos, a saber, Estados Unidos y Canadá han establecido controles relativamente fuertes contra la polución. Por otro lado, no es extraño que países de grandes poblaciones y con pequeños PGBs como la India y China, lleguen a ser muy pronto los contaminadores dominantes del planeta, ya que estas naciones en desarrollo no han estado precisamente en los frentes de las reformas medio ambientales. Sin considerar el nivel de desarrollo en el que los propios países se encuentran, éstos todavía tienden a considerar los costos políticos muy altos como para considerar la retribución que pueda otorgarles el desarrollo de políticas de protección del medio ambiente.

\section{Organizaciones Intergubernamentales (OIGs)}

Naciones Unidas es la principal organización intergubernamental que promueve políticas medio ambientales globales. Algunas organizaciones de $\mathrm{Na}-$ ciones Unidas están relacionadas directamente con temas del medio ambiente desde perspectivas generales a especializadas. De esta forma, nos encontramos con la Conferencia de Naciones Unidas sobre el Ambiente y Desarro1lo(UNCED); el Programa de Naciones Unidas sobre el Medio Ambiente; la Conferencia de Naciones Unidas sobre Desarrollo Humano y el Comité sobre Comercio y Medio Ambiente de la Organización Mundial de Comercio. Hay otras organizaciones que tienen incidencia en los temas medio ambientales aun cuando éstos no son sus objetivos primarios. En este ámbito destacan el Programa de Desarrollo de Naciones Unidas; la Conferencia de Naciones Unidas de Desarrollo Sostenible; el Banco Mundial; la Organización Mundial de la Salud y la Organización Mundial Metereológica.

La Conferencia de Naciones Unidas sobre Medio Ambiente y Desarrollo (UNCED) emergió como un organismo de vanguardia de Naciones Unidas para la búsqueda de acuerdos globales sobre temas del medio ambiente en 1992 durante la Conferencia de Río- también conocida como la Cumbre de la Tierra- la cual elaboró un conjunto amplio de recomendaciones en materias relacionadas con el medio ambiente y el desarrollo. Uno de los objetivos especiales de la Conferencia fue alcanzar un acuerdo global en el manejo de los bosques del mundo. Sin embargo, en dicha ocasión no fue posible lograr ningún acuerdo específico. En cambio surgieron una serie de recomendaciones 
amplias no vinculantes y obligatorias para los estados. Los líderes de Naciones Unidas descubrieron muy a su pesar que aun cuando las más poderosas naciones del mundo desearan soluciones ellas podían ser bloqueadas por naciones en desarrollo relativamente débiles. Los Estados Unidos desearon, en dicha oportunidad, una Convención de Manejo del Bosque que pudiera proteger los recursos forestales en el mundo, pero Indonesia, Brasil y Malasia rehusaron cooperar en este sentido ${ }^{7}$.

El último intento por alcanzar un acuerdo amplio en el tema medio ambiental fue la Cumbre de Tokio, Japón, en diciembre de 1997. Esta Cumbre fue organizada por Naciones Unidas y asistieron 159 países. Los participantes se dividieron en dos campos, aquellos que deseaban un acuerdo modesto, incremental y flexible, para disminuir las emisiones de gas y aquellos participantes que querían un documento firme y poderoso en términos de establecer estándares amplios y específicos sobre la materia. Mientras que la mayoría de los países reconocieron que el calentamiento global de la tierra debía ser tomado en serio, solamente los estados desarrollados estuvieron dispuestos a establecer costosas cuotas de reducción de emisiones.

El acuerdo final alcanzado en Tokio provee un interesante estudio en la diplomacia medio ambiental internacional. En efecto, aunque solamente 34 países desarrollados estuvieron de acuerdo en reducir las emisiones de gas a un siete - ocho por ciento para el año 2012 (Estados Unidos un siete por ciento y la Unión Europea un ocho por ciento), la revista The Economist sin embargo llamó a esta propuesta "la más ambiciosa hazaña de la diplomacia medio ambiental alguna vez intentada." ${ }^{8}$ A pesar de esta intención demostrada por algunos estados en dicha Cumbre, resulta poco probable que el Senado de Estados Unidos hubiera ratificado este acuerdo y es aun más dudoso que el nivel de reducción de gas pudiera ser alcanzado, incluso con aquellos que ratificaron el acuerdo. Cabe consignar que la mayoría de los países en vías de desarrollo no lo ratificaron.

Los líderes de los países desarrollados han discrepado por largo tiempo sobre los costos y factibilidad de limitar los gases del efecto invernadero y asimismo, sobre los beneficios de las diferentes políticas a adoptar. Antes de Tokio, los diplomáticos norteamericanos propusieron una reducción limitada

${ }^{8}$ Sobre un resumen de la Conferencia, véase The Economist (December 13, 1997) 13 
y gradual que al año 2010 significara retornar a los niveles de 1990. Alemania insistió que existía nueva tecnología disponible como para permitir en forma significativa índices más altos de reducción. Para los Estados Unidos esto parecía poco realista, aunque Alemania ha disminuido sus emisiones desde 1991 en doce por ciento. Sin embargo, algunos estiman que esto se debe principalmente a las altísimas tasas de polución provenientes de las fábricas de Alemania del Este.

Con todo, los científicos están prediciendo ahora que el uso comercial de altas tecnologías (células PEM) en los motores de los automóviles y otros vehículos, acompañados con la aplicación de poderes fotovoltaico y viento, podría alterar significativamente los pronósticos de los cambios de tiempo durante el Siglo XXI.

\section{Organizaciones Civiles No Gubernamentales (ONGs)}

Muchas organizaciones de ciudadanos están involucradas con agencias de gobierno y corporaciones empresariales en la planificación y formulación de políticas que afectan la calidad de vida en el área del medio ambiente. Estas incluyen varias organizaciones privadas sin fines de lucro que han establecido vínculos globales para formular en forma más efectiva políticas locales. Entre las más conocidas y más efectivas de estas organizaciones sobresalen La Fundación Mundial de Fauna Silvestre (con su sede central en Ginebra y con agencias en los Estados Unidos y veinte y ocho otros países) la Oficina Medio Ambiental Europea, Sierra Club, la Sociedad Nacional Audubon, la Federación Nacional de Fauna Silvestre, el Fondo de Defensa Medio Ambiental, el Instituto World Watch, el Instituto de Recursos Mundiales y Greenpeace.

Estas organizaciones, tomadas colectivamente, han ayudado a influenciar la formulación de las políticas globales sobre el medio ambiente en dos formas. En primer lugar ellas han contribuido a construir bases de datos y a proveer un mejor conocimiento y entendimiento de los temas. Es más, en algunas oportunidades estas organizaciones formulan nueva legislación y proponen esquemas más creativos para la comprensión de las relaciones entre intereses regionales, temas ambientales y acuerdos globales. En segundo término, dichas organizaciones realizan lobbies con los gobiernos y otras organizaciones para que lleguen a ser más sensibles con los temas del medio ambiente. También organizan campañas educativas, boicots y litigios. Aunque 
algunas de estas organizaciones (tales como Sierra Club y la Sociedad Nacional Audubon) han estado activas durante la mayor parte del siglo XX ellas han llegado a ser un elemento nuevo y significativo en la influencia de políticas en el nivel global. Las corporaciones multinacionales han estado también organizadas en grupos de presión con el fin de maximizar su influencia en la arena política.

\section{Marcos interpretativos o esquemas que explican las políticas del medio ambiente}

Existen cuatro esquemas o marcos interpretativos muy sugerentes en los ámbitos social, económico, seguridad y moral para entender las políticas globales medio ambientales. Tales referentes ofrecen perspectivas útiles sobre las políticas acerca de los temas que preocupan en esta materia. Estos marcos explicativos nos ayudan también a enfocar el problema desde las relaciones sociales, estrategias de mercado, políticas de seguridad nacional y global y también, a partir del papel que la religión y la ética secular desempeñan en este campo.

El Marco Social sitúa a las personas y sus interacciones sociales con el medio ambiente en el centro de la discusión. El tema aquí no es primeramente qué productivo puede ser el mercado. Se asume que la tierra contiene suficientes recursos para sustentar a la actual población y aun a un número mayor de gente en el mundo. Esta perspectiva no necesariamente considera al tema de la población en términos de presiones calamitosas sobre los recursos de la tierra. Es más, aquellos que argumentan desde esta perspectiva, creen que la discusión más significativa y relevante está centrada en los lazos existentes entre la comunidad y cultura. Debido a que los seres humanos son inseparables de su entorno, el marco interpretativo adecuado es el humano y éste incluirá inevitablemente el medio ambiente y su protección.

Por otra parte, todas las sociedades han desarrollado un conjunto específico de actitudes hacia el medio ambiente. Los optimistas asumen los beneficios que la ciencia ya ha aportado al planeta. ${ }^{9}$ Piensan que la expansión global de la economía (aun con el doble de una población estimada en 5.8 billones en 1977) no significará un desastre. Del mismo modo observan un progresivo mejoramiento del medio ambiente en el largo plazo. Aun cuando 
reconocen que la desaparición arbitraria de muchas especies se está incrementando en una tasa alarmante, creen que esta situación podría ser revertida también con el tiempo.

Por último, los optimistas también están, al mismo tiempo de acuerdo que el rápido incremento del calentamiento global de la tierra y la expansión del agujero de ozono son preocupantes, pero no ven a éstos fenómenos como causas de pánico y respuestas sin consideración. Los optimistas se basan en la velocidad y naturaleza de los mejoramientos del pasado en la condición humana y en los potenciales beneficios de la ciencia para ayudar a los hombres a entender y mejorar el ecosistema. Esta perspectiva se centra en el crecimiento de la población con la extensión de los ciclos de vida, la eliminación de enfermedades, el mejoramiento de las comunicaciones y el transporte y el crecimiento de las grandes ciudades como centros sofisticados de intercambio económico y cultural.

No todo el mundo, sin embargo, observa la flexibilidad y adaptabilidad del sistema social con tal optimismo. Si la tierra tiene una limitada capacidad de conducción, los seres humanos usarán eventualmente los recursos no renovables y deberán enfrentar el problema de un ecosistema que colapsa. Podrá haber un retraso en el impacto negativo sobre el medio ambiente, pero eventualmente la comunidad humana sufrirá como consecuencia de esta opción. Algunos especialistas han pronosticado que la tierra muy pronto alcanzará su capacidad de sostenimiento y claman entonces por esfuerzos extremos de control de la población. ${ }^{10}$

Mientras algunos ven a la población como el más grande problema individual que enfrentará el mundo en el presente Siglo XXI, otros creen que la brecha en riqueza y salud es el más serio problema y que ésta es un tema cultural y moral. Dichos problemas no son solamente una materia de recursos naturales y geografía, ya que los rasgos sociales, culturales y morales son los que generalmente determinan diferencias básicas dentro y entre países ricos y pobres. ${ }^{11}$

9 Dennis Avery, "The Myth of Global Hunger," The World and I (January, 1997), reimpreso en Theodore D. Goldfarb, ed., Taking Sides. Clashing Views on Controversial Environmental lssues (8th ed. Guilford, Conn.: Dushkin Publishing Group, 1988) 359-63. Véase también Julian L. Simon, " More People, Greater Wealth, More Resources, Healthier Environment," una versión de Economic Affairs (Abril 1994) reimpreso en Theodore D. Goldfarb, ed., Taking Sides. Clashing Views on Controversial Environmental Issues (7th ed. Guilford, Conn.: Dushkin/Mc Graw Hill, 1997) 187-96

"Lester R. Brown, "Analyzing the Demographic Trap," en idem, director de proyecto, State of the World 1987: A Worldwatch Institute Report on Progress Toward a Sustainable Society (New York: W.W. Norton, 1987) 20-37 "David S. Landes, The Wealth and Poverty of Nations (New York: W.W Norton,1998) 
El Marco Económico provee una perspectiva que es más focal y específica que la social. La explicación económica sitúa a las relaciones de mercado en el centro de cualquier planificación global futura. Los economistas liberales, por su parte, estiman que el papel político de los estados debería reducirse en cuanto a la regulación del sistema global como así también la tendencia natural de los políticos de interferir en las fuerzas del mercado. Los liberales creen que la economía es el marco apropiado para pensar acerca del medio ambiente y por lo tanto que la actual estructura global facilitará políticas constructivas sobre la misma materia.

Sin embargo, este optimismo contrasta con aquellas visiones, también liberales, que se muestran un tanto escépticas frente a las políticas de mercado para combatir la polución ambiental. En efecto, a partir de una comparación entre las opciones clásicas y modernas del liberalismo, Barry Clark sostiene que mientras la primera se concentra en una relación de intercambio entre protección del consumo y el medio ambiente, el enfoque moderno estima que las políticas medio ambientales sanas pueden ser consistentes y congruentes con el crecimiento económico y con el logro de más altos estándares de vida.$^{12}$

En otras palabras, los liberales modernos tienden a favorecer políticas del medio ambiente que sean tanto justas como eficientes. En este sentido, en un esfuerzo por alcanzar equidad, un medio ambiente limpio debería ser tratado como un derecho humano al cual todas las personas tengan acceso sin considerar su capacidad de pago en el mercado. Del mismo modo, una gran proporción de la carga financiera para el control de la polución debería estar concentrada en los miembros más ricos de la sociedad ${ }^{13}$.

En consecuencia, la primera interrogante que plantean los liberales en este campo es hasta qué punto la población está creciendo demasiado rápido en el planeta, particularmente en el Sur globalizado. Una respuesta sugerida por esta visión apunta a cambiar las políticas de inmigración y permitir que el Norte interdependiente absorba el exceso de personas hasta que las estrategias económicas ayuden a ajustar la brecha entre el Norte y el Sur. Incluso ha insinuado, que la caída de las tasas de fertilidad como en Italia y Alemania pueden producir un nuevo conjunto de problemas para el futuro. ${ }^{14}$

${ }^{12}$ Barry Clark, Political Economy, A Comparative Approach (Westport, Ct: Praeger Publishers, 1991) 266-269

${ }^{13}$ Esta visión liberal es desarrollada por Daniel R. Mandejker en su libro Environment and Equity: A Regulatory Challenge ( N.York: McGraw-Hill, 198i). A este respecto ver Barry Clark, op. cit., 268

$"$ Barbara Crossette, "How to Fix a Crowded World: Add People," New York Times Week in Review (November 2, 1997) 1 
No todos los economistas están de acuerdo con el optimismo de la anterior formulación y predicción. Algunos ofrecen una crítica radical al orden económico vigente ${ }^{15}$. Entre los factores negativos que esta posición resalta sobresale la integración de la economía global, la existente- algunos dirían creciente- disparidad entre naciones ricas y pobres (las últimas representando a la mayoría de la población mundial) y el poder de las corporaciones multinacionales, todos éstos, como problemas prioritarios que necesitan ser resueltos con los cambios estructurales globales.

Una respuesta a esta adversidad económica mundial es la que ofrece la perspectiva estructuralista al postular reformas importantes al sistema internacional. Estas apuntan preferentemente a reformular la ayuda externa, la protección económica y el acceso a los mercados del Norte. En general, postula que la industrialización puede ser alcanzada en el contexto de un mercado internacional reformado y que tal proceso ayudará a estrechar la brecha del desarrollo ${ }^{16}$. Solamente después que las disparidades estructurales hayan sido resueltas podrán ser abordados adecuadamente los problemas del medio ambiente.

Tanto los economistas liberales como los radicales advierten contra la estrecha y limitada focalización en los temas medio ambientales, así como ịnhibir el desarrollo económico y perder la visión de la centralidad de los temas económicos. Estas materias deberían resaltar los problemas crecientes que presentan los bosques en Brasil e Indonesia. En otras palabras, para los economistas los esfuerzos para reducir los incendios y destrucción de los bosques han fracasado porque los temas económicos no fueron propiamente tratados.

El Esquema de la Seguridad se centra en la dimensión política del sistema global. Los defensores de este marco interpretativo se basan en la seguridad como un término global que incluye aspectos sociales, económicos y políticos ${ }^{17}$. Al igual que los defensores de la interdependencia, aquellos que se concentran en la seguridad argumentan que la tarea principal del gobierno, de los líderes civiles y sus respectivas instituciones es reinterpretar la seguridad desde una perspectiva global.

\footnotetext{
15 André Gunder Frank y otros teóricos de la dependencia no muestran preocupación con los temas ambientales. Ellos más bien se concentran primariamente en resolver las desigualdades y disparidades económicas. Sobre este particular, véase André Gunder Frank, "World System in Crisis," en William R. Thompson, ed., Contending Approaches to World System Analysis (Beverly Hills: SAGE, 1983) 27-42

${ }^{16}$ Joan Edeiman Spero, The Politics of International Economic Relations ( 4 .ed. New York: St. Martin's Press, 1990). "Vếase, e.g., Jessica Tuchman Mathews, "Redefining Security," Foreign Affairs 68, № 2 (Spring 1989) 167-77
} 
Para ello sostienen que la competencia por el poder (sea militar, política o económica) llevará inevitablemente a conflictos y guerra, violencia y terrorismo, a menos que los problemas ambientales globales sean abordados en un marco amplio y colectivo de gobierno y cooperación internacional. Es más, en la actualidad se sostiene que el cambio del medio ambiente global, unido a una serie de problemas complejos e interdependientes como la pobreza, el crecimiento demográfico y la desigualdad, constituyen los nuevos problemas de seguridad internacional.

Por lo tanto, la degradación ambiental ya no sólo debe considerarse como una consecuencia posible de guerras ( Laos, Cambodia en los sesenta y más recientemente la Guerra del Golfo) sino que también y, probablemente en forma creciente, como las causas de serios conflictos internacionales. En otras palabras, desde el momento en que los recursos naturales son destruidos, lo más probable es que se agudizará el conflicto entre aquellos que dependen de dichos recursos. Del mismo modo, el avance de los desiertos y el colapso ecológico producirán eclosiones sociales y económicas como fuertes movilizaciones poblaciones cuyas consecuencias seguramente significarán amenazas a la seguridad en la forma más tradicional. ${ }^{18}$

Lo anterior ha sido enfatizado por numerosas comisiones de expertos, pero una de las formulaciones más convincentes proviene de la Comisión Brundtland (también conocida como la Comisión Mundial sobre el Medio Ambiente y Desarrollo) que fue creada por la Asamblea General de Naciones Unidas en 1987. Esta instancia internacional, a través de la publicación de su informe "Nuestro Futuro Común", proveyó a la humanidad de una influyente señal de advertencia y llamado para la acción. Entre lo más significativo, acuñó el lema «desarrollo sustentable» como un intento para reconciliar el conflicto entre crecimiento y conservación ambiental, el que venía siendo persistente en la discusión internacional desde la Conferencia de Naciones Unidas sobre Ambiente Humano realizada en Estocolmo en 1972.

De esta forma, sin negar que el control de armas es un componente esencial de este marco global sobre la seguridad, estos especialistas enfatizan que encontrar una solución al calentamiento global de la tierra, a la disminución del ozono y a la degradación del agua y los bosques es fundamental para la

¿3 John Vogler, "Environment and Natural Resources," en Brian White, Richard Little y Michael Smith, edts., Issues in World Politics (London: MacMillan Press, Ltd, 1997) 243-44 
seguridad futura e indispensable para un desarrollo efectivo y sustentable. Esta explicación reconoce una alta prioridad al carácter de tragedia que encierran estos problemas para el futuro de los pueblos globales, al menos que la mayoría participe y que no solamente se involucren unos pocos actores locales o individuos entusiastas.

El Marco Moral. El papel de la moralidad en la política ha sido poderosamente influenciado en los Estados Unidos por los realistas políticos quienes han insistido siempre que en el contexto de la seguridad nacional (especialmente durante la Guerra Fría) no hay bienes morales o malas políticas, solamente seguridad y supervivencia. "Buenas" políticas son aquellas que aseguran la supervivencia global y la seguridad nacional. "Malas" políticas, en cambio, no alcanzan a asegurar los bienes antes señalados. George F. Kennan articuló esta política en forma efectiva, cuando escribió que un estado soberano es legítimo siempre que sea capaz de garantizar "las bendiciones de la seguridad militar, la prosperidad material y... el propósito de la felicidad. Para estos supuestos el gobierno no necesita justificación moral..."19 Además, desde que no existen normas y parámetros morales globalmente aceptados, cada gobiemo defiende sus políticas en el contexto de su propio marco moral.

Dicho de otra manera, los realistas se preocupan menos de lo que es moralmente correcto que de lo que es pragmáticamente posible. Así por ejemplo, Estados Unidos debería promover un mundo abierto no porque sea "correcto" sino porque está en el interés nacional del país hacerlo ${ }^{20}$.

Desde que los temas medio ambientales requieren en forma creciente esquemas globales para alcanzar soluciones satisfactorias en los niveles económicos, políticos y sociales, es más apropiado, entonces, que una respuesta amplia y comprehensiva a los temas globales debe incluir también la relación entre el cambio ambiental, justicia social y moralidad. Las instituciones políticas que son instrumentales en garantizar la seguridad y felicidad e (incrementalmente) la salud medio ambiental, están enraizadas en culturas religiosas. Aun en los llamados ámbitos seculares, los orígenes de la vida política son visiblemente religiosos. Así como la moralidad fue instrumental en legitimar el capitalismo, hoy se le exige humanizarse. La moralidad también expresa y configura los autoentendimientos y valores básicos de las llamadas

\footnotetext{
19 George F. Kernan, At a Century"s Ending. Reflections 1982-1995 (New York: W.W. Norton, 1996) 274

${ }^{20}$ Torbjörn L. Knutsen, A History of International Relations Theory (Manchester: Manchester University press, 1992) 239
} 
sociedades "socialistas" (donde el bien colectivo es considerado más importante que la expresión individual).

Los últimos movimientos de reforma en Europa Central y Rusia se originaron en las preocupaciones por los derechos humanos y temas medio ambientales, cuyas raíces se encuentran en el entendimiento cristiano, judío e is-lámico del mundo y en los valores éticos que configuraron la comprensión de los seres humanos en esas regiones del planeta. Aun en China, Cuba, Vietnam y Corea del Norte las bases morales de los gobiernos que todavía reclaman representar el bien común, descansan en complejos sistemas éticos que son más antiguos que el Cristianismo, Judaísmo y el Islam. Mientras que para los especialistas ha llegado a ser un lugar común describir a las instituciones políticas contemporáneas en sus orígenes culturales, es todavía raro situar a los temas medio ambientales dentro de un esquema moral. Un autor en esta vertiente explica cómo la visión cristiana de lo simple, de la humildad y justicia puede ayudar a comprender los problemas ecológicos y guiar al proceso político ${ }^{21}$.

En la medida en que severos desastres y quiebres medio ambientales lleguen a ser más comunes en el sistema internacional - el desastre nuclear de Chernobyl en la Unión Soviética, la destrucción total ecológica del mar de Aral en Rusia, la masiva deforestación en Brasil e Indonesia, la desaparición de especies en Borneo y América Central, para nombrar algunos ejemplos los gobiernos y las organizaciones internacionales tendrán la capacidad de abordarlos y corregirlos, solamente si consideran las implicaciones morales de tales calamidades y aseguran el poderoso apoyo y respaldo en sus esfuerzos de las organizaciones religiosas.

\section{Desafios medio ambientales y respuestas políticas que se proponen}

Existen tres categorías de desafíos que enfrenta cualquier actor del sistema intelectual que participa en un régimen medio ambiental si desea formular una efectiva legislación en este campo: desacuerdos fundamentales, la

\footnotetext{
${ }^{21}$ Matthew Baasten, "Christian Values, Technology, and the Environmental Crisis (véase arriba,pp. 99-124). Ver tambiën Fen Osler Hampson y Judith Reppy, eds., Earthly Goods: Environmental Change and Social Justice (Ithaca, N.Y: Cornell University Press, 1998)
} 
brecha entre naciones ricas y pobres y el derecho internacional. La primera categoría consiste en desacuerdos fundamentales y básicos sobre la velocidad e intensidad de la degradación medio ambiental y los costos estimados de una política efectiva. La segunda categoría consiste en el desafío derivado de la continua disparidad entre naciones ricas del Norte y las pobres del Sur y la relativa responsabilidad de las naciones de trabajar en forma conjunta por una solución. La disparidad entre países ricos y pobres establecen serios obstáculos a una legislación efectiva sobre la materia.

La tercera categoría de desafíos corresponde a la del campo de los estudios interdisciplinarios y del Derecho Internacional. Aun cuando han sido creados algunos pocos regímenes internacionales para responder a los temas medio ambientales y que han sido codificados en el Derecho Internacional (Derecho del Mar, por ejemplo) éstos no son muy eficaces. En efecto, existe una aguda disparidad entre la formulación de las teorías y la aplicación y cumplimiento de la ley internacional. Muchas naciones en desarrollo argumentan que no pueden asumir los costos de la protección del medio ambiente hasta no alcanzar un alto grado o nivel de desarrollo. En consecuencia, estas naciones pretenden ser autónomas y actuar libremente acerca de esta materia en el escenario internacional. Para evitar estas disparidades, es necesario entonces, un acuerdo entre estados naciones con el fin de establecer un código de conducta uniforme con autorización de acuerdo a los niveles de desarrollo y asimismo, con consideraciones de justicia social.

\section{Desacuerdos acerca de Objetivos y Soluciones}

Los desacuerdos sobre el significado y dirección de la degradación ambiental y los costos reales de soluciones efectivas son intensas y amplias. Es imposible calcular la tasa e intensidad del desarrollo de las economías de China e India (naciones que representan un tercio de la población mundial) y cómo su crecimiento y desarrollo económico afectan a las emisiones totales de gases peligrosos. Los rápidos y sostenidos esfuerzos de los países en desarrollo por industrializar sus economías sin atender los efectos de polución será uno de los más temibles desafíos para la creación de regímenes medio ambientales efectivos en el presente siglo XXI. Tan pronto como el mundo desarrollado comenzó a hacer algunos progresos tecnológicos, la "industria del carbón fósil" floreció en las naciones en desarrollo agregando vastas y 
nuevas fuentes de polución. Para los ciudadanos de estas naciones, la alternativa es generalmente entre polución o inanición. En otros términos, enfrentadas a tales opciones, dichas naciones seleccionarán la polución, sin perjuicio de sus convicciones económicas o morales.

Estados Unidos continúa siendo el país que ofrece el liderazgo más poderoso para los acuerdos ambientales y en la actualidad constituye el mayor obstáculo a negociaciones serias en el campo del medio ambiente. ${ }^{22}$ Por ejemplo, este país ha rehusado ratificar la Convención de Basilea (1989) sobre la transferencia de desechos peligrosos, oponiéndose de esta manera a la Convención de Biodiversidad de la Conferencia de Río de 1992. Finalmente, Estados Unidos dilató su decisión para que después, en forma renuente, sumara su apoyo a la Global Environmental Facility (GEF).

Una fórmula limitada, pero práctica para resolver los desacuerdos existentes sobre el tema que nos preocupa ha resultado de las negociaciones sobre la GEF iniciados por los países europeos en 1991 y respaldados por el Banco Mundial. Este mecanismo propone apoyar y desarrollar asistencia técnica y científica a proyectos que pudiesen reducir la degradación ambiental con el mínimo de daño a las economías de países ricos y pobres. Después de años de discutir y regatear sobre la dirección institucional y el control administrativo de GEF por los líderes de las naciones pobres y desarrolladas se alcanzó una solución satisfactoria. La discusión y resolución de visiones contrapuestas y disputas en torno a muchas diferencias existentes entre las naciones donantes y las receptoras de ayuda sobre áreas específicas del medio ambiente sugiere que un marco realista como el mecanismo del GEF puede ser establecido a nivel global..$^{23}$

\section{Disparidades}

Los desacuerdos que surgen acerca de las políticas medio ambientales, sus costos y financiamiento, están fuertemente afectados por la continua disparidad entre las naciones post-modernas como Estados Unidos, Canadá y

\footnotetext{
${ }^{22}$ Konrad von Moltke, "Institutional Interactions: The Structure of Regimes for Trade and the Environment," en Oran R. Young, ed., Global Governance Drawing Insights from the Environmental Experience (Cambridge, Mass,: M.J.T. Press, 1998) 256

${ }^{23}$ M.J. Peterson, "International Organizations and the Implementation of Environmental Regimes," en Global Governance, $115-51$
} 
los países de la Unión Europea por un lado y, por otra parte, las naciones en vías de desarrollo y cuasi-modernas como México, Brasil, Chile, India, Turquía y Corea, para citar algunas. Aunque existe desacuerdo sobre los orígenes y naturaleza de esta disparidad, nadie niega que las diferencias relativas en poder y desarrollo de las naciones son grandes factores que influyen en las negociaciones sobre el medio ambiente. El Banco Mundial ha llegado a ser un líder entre las instituciones multilaterales negociadoras de estándares medio ambientales. Aunque no siempre éste fue el caso, el Banco Mundial después de décadas de recibir críticas por los ambientalistas ha implementado, desde 1995, algunos cambios de sus políticas que pueden permitir redirigir sus recursos hacia programas ambientales. ${ }^{24}$

Una respuesta al problema de la disparidad entre el Norte y Sur en la arena de la deforestación es el Plan de Implementación Conjunta (JIP). Esta propuesta fue iniciada por Estados Unidos y busca privatizar la polución global para proteger los bosques de los países en desarrollo. El Plan utiliza estrategias de mercado para incentivar a las industrias de los países ricos (las cuales pueden ser grandes contaminadoras) para invertir en la protección de bosques amenazados de los países pobres. Estas inversiones se hacen pagando impuestos de polución a ser usados en el respaldo de proyectos diseñados para salvar bosques. Uno de estos proyectos fue iniciado en Costa Rica y los fondos han sido usados para apoyar a los trabajadores quienes viven de los productos forestales.

\section{Derecho Internacional y Entendimiento Global}

Desde que las soluciones globales son fomentadas por un creciente número de problemas económicos, ambientales y políticos, tanto el derecho internacional como el entendimiento global crecen en importancia. Los protocolos internacionales llegarán a ser parte regular del proceso doméstico de formulación de políticas. Para que cada acuerdo ambiental multilateral tenga éxito, las leyes domésticas de los estados deberán ser transformadas con el objeto de complementarse con sus contrapartes globales. Sin embargo, la tarea de formulación

${ }^{24}$ David Reed, "The Environmental Legacy of Bretton Woods: The World Bank," en Global Governance, $227 \cdot 45$ 
de un cuerpo de derecho internacional coherente y consistente que sea respetado y acatado por las partes, está todavía en una fase incipiente.

El Centro de Derecho Ambiental de la Unión Internacional para la Conservación de la Naturaleza (IUCN) es una organización civil con una efectiva red global compuesta por varios científicos, abogados y especialistas en campos afines. Aunque la IUCN se concentra específicamente en la conservación de la vida silvestre y se preocupa por la desaparición de especies, esta organización sirve como modelo de coordinación de recursos y fortalecimiento del papel del derecho internacional en el ámbito medio ambiental.

\section{Reflexiones finales}

Este trabajo ha intentado mostrar como los temas ambientales han empezado a influir en las políticas públicas en varios niveles. La calidad futura de las comunidades humanas depende de la capacidad de los decidores políticos, no sólo para encontrar una nueva relación entre los actores nacionales e internacionales y el ecosistema global, sino que también para introducir un referente moral en tales políticas.

Un grupo de académicos y especialistas ha llamado recientemente a un nuevo marco ético para la formulación de políticas en el contexto del mercado mundial ${ }^{25}$. Para los realistas quienes llegaron a ser políticamente responsables durante la Guerra Fría, esto puede aparecer muy idealista, especialmente si se piensa que la creciente conciencia de la crisis global medio ambiental introducirá una nueva era de preocupaciones éticas. Este análisis podría alentarnos hacia una visión demasiado optimista. Del mismo modo, el mismo marco analítico "a-ético" que originó los excesos de la Guerra Fría aún permanece entre nosotros. La perspectiva realista permitió a los que toman las decisiones contaminar algunas de las áreas naturales del planeta y por lo tanto amenazar la existencia misma de nuestro ecosistema. Todos ello, en nombre de la defensa de los más altos valores del orden internacional.

En consecuencia, la tarea más urgente de hoy frente a los decidores, consiste en desarrollar una nueva ética para las políticas globales antes que colapse

2s Dorinda G. Dallmeyer y Albert F. lke, eds., Environmental Ethics and the Global Marketplace (Athens, Ga.: University of Georgia Press, 1998) 
el ecosistema bajo el peso del progreso y del desarrollo económico. ¿Pueden los científicos, profesionales y ambientalistas sanar las enfermedades que aquejan al ecosistema? Quizás, la "cura" debería ser precedida por el "cuidado." Con todo, para descubrir efectivas curas debemos primeramente redescubrir una nueva relación de prevención para el ecosistema. El "cuidado", distinto de la "cura", depende del reclamo de la verdad en el sentido de que nuestros mejores valores son la belleza y perfección. A menos que como especialistas nos demos cuenta que la supervivencia del medio ambiente no sea medido solamente por la producción y el crecimiento, sino que también por su fecundidad y cuidado, es poco probable que las políticas cambien de aquellas prácticas del pasado.

Un marco realista y pragmático para los problemas del medio ambiente debería incluir más que el poder y el control. Cuando el medio ambiente llegue a ser sagrado como la vida misma, el lenguaje del optimismo versus el del pesimismo podrá ser reemplazado con aquél de esperanza y de políticas efectivas que atesoren y protejan bien al ecosistema en el presente Siglo XXI.

Finalmente, el medio ambiente, desde una perspectiva geopolítica global, se nos presenta con el típico escenario de "buenas y malas noticias". La buena noticia de hoy es que por primera vez en la historia de la humanidad hemos llegado a reconocer que la devastación de la naturaleza no es solamente un problema local o regional sino que un fenómeno global y que debemos responder a este despertar. Conferencias internacionales como la Cumbre de la Tierra de 1992 en Río y la de Tokio sobre Calentamiento Global de la Tierra en 1997 son buenos ejemplos de respuesta a esta tendencia universal. La Naciones Unidas en particular han tomado el liderazgo en esta área con el Programa sobre Medio Ambiente y su Conferencia sobre Desarrollo Sustentable que originó "Nuestro Futuro Común". Este documento virtualmente estandarizó el lenguaje de "desarrollo sostenible" de la noche a la mañana.

También en el ámbito de las buenas noticias ha sobresalido la creación de acuerdos internacionales sobre el medio ambiente como el protocolo de Montreal de 1987 que busca limitar y reducir la producción de clorofloruros de carbón (CFCs) para evitar el deterioro de la capa de ozono. El primero de esta clase de acuerdo internacional, al parecer, está generando resultados positivos de momento en que un reciente reportaje científico sobre la materia indica que la cantidad de CFCs en la atmósfera se ha estabilizado y tiende a decrecer. ${ }^{26}$ Todos estos progresos sugieren el movimiento práctico y global 
hacia lo que los Obispos de la Iglesia Católica de Estados Unidos han llamado "El bien común planetario" 27.

Por otra parte, es posible también constatar malas noticias, las cuales este ensayo ha tratado de resumir. En primer lugar, existe una realidad de serios desacuerdos internacionales sobre la velocidad, intensidad y costo de la destrucción ecológica. Esto fue recientemente ejemplificado en la falta de acuerdo sobre calentamiento global de la tierra en la Conferencia de Tokio. En seguida, existe una disparidad económica entre las naciones desarrolladas del Norte y las en procesos de desarrollo del Sur. Este "nudo gordiano" evoca la inevitable observación que, globalmente, las soluciones ecológicas están inextricablemente conectadas a la justicia socioeconómica.

En su Día Mundial de la Paz en 1990, el Papa Juan Pablo II declaró que "el balance propiamente ecológico no se encontrará sin que se aborden directamente las formas estructurales de pobreza que existen alrededor del mundo." ${ }^{28}$ La Declaración de la Iglesia Católica de Estados Unidos "Renewing the Earth"(1991) y el documento de la Iglesia Presbiteriana de Estados Unidos "Hope for a Global Future: Toward Just and Sustainable Human Development" (1996) también apoyan esta visión. De esta forma si el peso completo de la perspicacia y juicio teológico es llevado a este problema internacional, el peso de la carga y la responsabilidad por alcanzar una solución al impasse Norte-Sur cae en las naciones ricas del Norte. Después de todo, ellos representan una minoría de la población del mundo pero consumen la gran mayoría de los recursos de la tierra y producen la mayor parte de la polución mundial. ${ }^{29}$

En consecuencia, es crucial que las iglesias del Norte continúen e incrementen sus esfuerzos para persuadir a las naciones desarrolladas de asumir un liderazgo responsablemente progresivo y paraforjar nuevas formas y

\footnotetext{
26 Estas promisorias noticias provienen de un informe-borrador para ser publicado por la Organización Mundial Metereológica, la agencia especializada de Naciones Unidas sobre la materia. Vêase el reportaje de noticias "Damaged Atmosphere Begins to Heal," The Oregonian (October 1, 1998)

27 "Renewing the Earth" Origins (December 12, 1991) 429

${ }^{28}$ John Paul II, The Ecological Crisis: A Common Responsibility (Washington, D.C.: U.S. Catholic Conference, 1990), ${ }^{29}$ Sobre este punto, un buen caso es el consumo de energía en los Estados Unidos. Con el seis por ciento de la población del mundo, este país consume aproximadamente el treinta por ciento de toda la energía del mundo. Los Estados Unidos también produce el $50 \%$ de los desechos tóxicos del mundo y $25 \%$ de las emisiones de dióxido de carbono en el planeta. De acuerdo a Daniel Chiras, "sobre bases per cápita, los norteamericanos consumen más del doble de la energïa consumida por la poblaciốn de Japón y Europa Occidental y, cerca de 16 veces mâs per cápita que la población de las nacjpnes en desarrollo," Véase Daniel D. Chiras, Environmental Science: Action for a Sustainable Future $(4$ ed. Redwood City, Calif.: Benjamin/Cummings,1994) 243-44.
} 
creativas de solidaridad internacional que alivien la pobreza estructural y la destrucción ecológica. Asimismo, esta nueva estrategia ética política ha sido reiterada por la Conferencia de Obispos Católicos de Estados Unidos, quienes han exigido a los responsables de la política mundial un auténtico desarrollo de las naciones pobres del Tercer Mundo que no sólo debiera preservar los recursos de la tierra para todos y reducir al mismo tiempo la polución y degradación medio ambiental, sino que también disminuir el impacto del crecimiento o declinación de la población sobre el medio ambiente y sobre el proceso total de desarrollo. ${ }^{30}(29)$

La globalización de la vida económica y los problemas ecológicos indicados en este trabajo también desafían el entendimiento tradicional del bien común. La noción del "bien común planetario" incorporado en "Renewing the Earth", tiene un gran mérito en este sentido, puesto que como recordáramos, provee desde una perspectiva ecológica y teológica, el deber de incorporar todo lo de la creación, tanto lo humano como también lo no humano. Globalmente, el primer obstáculo para el Siglo XXI será asegurar un equilibrado balance entre justicia socioeconómica para las comunidades en desarrollo y justicia ecológica para toda vida sobre el planeta Tierra.

$3^{30}$ Ver "The Harvest of Justice is Sown in Peace" ( November 17, 1993) en Gerard F. Powers, Drew Christiansen y Robert T. Hennemeyer, eds. Peacemaking; Moral and Policy Challenges for a New World (Washington, D.C.: U.S. Catholic Conference, 1994) 328. 